\section{THU0414 COMPARISON OF INTRA-ARTICULAR SHAM AND VEHICLE INJECTIONS FROM A PHASE 2B TRIAL OF SM04690, A SMALL-MOLECULE WNT PATHWAY INHIBITOR FOR KNEE OSTEOARTHRITIS}

Yusuf Yazici ${ }^{1}$, Jeyanesh Tambiah ${ }^{1}$, Christopher Swearingen ${ }^{1}$, Sarah Kennedy ${ }^{1}$, Vibeke Strand ${ }^{2}$, Brian Cole $^{3}$, Marc Hochberg ${ }^{4}$, Raveendhara Bannuru ${ }^{5}$, Timothy Mcalindon ${ }^{5} .{ }^{1}$ Samumed, LLC, San Diego, United States of America; ${ }^{2}$ Stanford University School of Medicine, Stanford, United States of America; ${ }^{3}$ Rush University, Chicago, United States of America; ${ }^{4}$ University of Maryland, Baltimore, United States of America; ${ }^{5}$ Tufts Medical Center, Boston, United States of America

Background: Intra-articular (IA) saline, commonly used as a placebo (PBO) comparator in knee osteoarthritis (OA) trials, has consistently shown improvements from baseline in patient-reported outcomes (PROs). ${ }^{1}$ These effects have been attributed to contextual and/or physiological benefits of saline, thus causing interpretation of potential IA therapeutics trial results to be questioned. ${ }^{2,3}$

Objectives: A prospective, randomized, controlled, 24-week phase $2 b$ study compared effects of vehicle PBO to sham and SM04690 (an IA Wnt pathway inhibitor in development as a potential disease-modifying knee OA drug (DMOAD)) injections. Potential unblinding impact of PBO or sham was also tested. Primary study results are presented separately. Methods: Knee OA subjects with Kellgren-Lawrence (KL) grades 2-3 and Pain Numeric Rating Scale (NRS) $\geq 4$ and $\leq 8$ in the target knee and $<4$ in the contralateral knee were randomized to receive a single blinded IA injection of $2 \mathrm{~mL}$ vehicle (PBO, $0.5 \%$ carboxymethylcellulose sodium, $0.05 \%$ polysorbate 80 in $\mathrm{pH} 7.4$ saline), sham (dry needle), or SM04690 in the target knee on Day 0. PROs included change from baseline in weekly average of daily pain in the target knee by NRS, Western Ontario and McMaster Universities Osteoarthritis Index (WOMAC) Pain, WOMAC Physical Function, and Patient Global Assessment (PtGA). Subjects were asked which treatment assignment they thought they received; their accuracy was compared using Bang's Blinding Index (BBI), a method used to evaluate blinding across clinical trial treatment arms. The index scale is $-1<0<+1$, with values toward -1 indicating more subjects incorrectly guessing treatment allocations, toward 0 indicating perfect blinding, and toward +1 indicating more subjects correctly identifying treatment allocations.

Results: In the full analysis set of PBO and sham subjects (N=233; 207 [89\%] completed), both groups showed clinically relevant improvements $\left(>10 \%\right.$ of full scale ${ }^{4}$ ) from baseline at first measurement that persisted through Week 24. However, no clinically meaningful or statistically significant differences were evident between the two groups at any timepoints (Figure). BBI did not indicate unblinding.

Conclusion: Subjects with knee OA receiving a single IA injection of PBO reported no differences in changes from baseline in knee OA PROs compared to subjects who received sham injections. These data suggested the effects were "contextual," meaning they resulted from the injection procedure, rather than from direct therapeutic effects of $\mathrm{PBO}$ or saline in the joint.

\section{REFERENCES:}

[1] Altman RD, et al. Semin Arthritis Rheum. 2016;46:151-9

[2] Zou K, et al. Ann Rheum Dis. 2016;75:1964-197

[3] Bannuru R, et al. Ann Intern Med. 2015;163(5):365-72

[4] Devji, Tahira, et al. BMJ open 7.5 (2017): e015587.
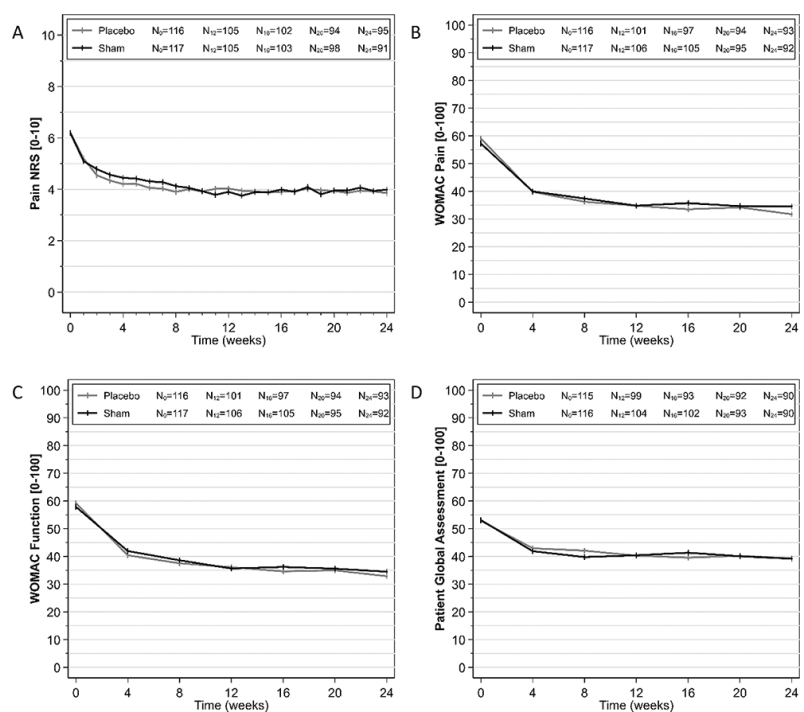

Figure: Observations over time depicting mean improvements $( \pm 95 \% \mathrm{Cl})$ of $\mathrm{PBO}$ compared to sham injection adjusted for baseline. A. Pain NRS, B. WOMAC Pain, C. WOMAC

Function, and D. Patient Global; in all subjects.

Disclosure of Interests: Yusuf Yazici Shareholder of: Samumed, LLC, Consultant for: Celgene Corporation, BMS, Genentech, Sanofi, Employee of: Samumed, LLC, Jeyanesh Tambiah Shareholder of: Samumed, LLC, Employee of: Samumed, LLC, Christopher Swearingen Shareholder of: Samumed, LLC, Employee of: Samumed, LLC, Sarah Kennedy Shareholder of: Samumed, LLC, Employee of: Samumed, LLC, Vibeke Strand Consultant for: Samumed, LLC, AbbVie, Amgen, EMD Serono, Eupraxia, Flexion, Iroko, Novartis, Pfizer, Regeneron, Sanofi, SKK, Brian Cole Shareholder of: Ossio, Regentis, Grant/research support from: Aesculap/B. Braun, Arthrex, Inc, Regentis, Consultant for: Arthrex, Inc, Regentis, Samumed LLC, Marc Hochberg Shareholder of: BriOri Biotech, Theralogix LLC., Consultant for: Bristol Myers Squibb, Eli Lilly, EMD Serono, Novartis Pharma AG, Pfizer Inc., Samumed LLC, Symic Bio Inc., Theralogix LLC, TissueGene Inc., TLC Biopharmaceuticals, Inc., Zynerba, Galapagos, IQVIA, Hoffman LaRoche., Raveendhara Bannuru Consultant for: Samumed, LLC, Bioventus, Timothy McAlindon Grant/research support from: Samumed, LLC, Consultant for: Samumed, LLC, Astellas, Flexion, Pfizer, Regeneron,

Seikugaku

DOI: 10.1136/annrheumdis-2019-eular.4454

\section{THU0415 EXPLORATORY PROTEIN PROFILING OF HUMAN SYNOVIAL FLUID FROM KNEE OSTEOARTHRITIS}

Neserin Ali ${ }^{1}$, Jon Tjörnstrand ${ }^{2}$, Paul Neuman ${ }^{2}$, Elin Folkesson ${ }^{1}$, Velocity Hughes ${ }^{1}$, Patrik Önnerfjord 1 , Martin Englund ${ }^{1} .{ }^{1}$ Lund University, Lund, Sweden; ${ }^{2}$ Skåne University Hospital, Lund, Sweden

Background: There is a lack of valid and robust biomarkers in the field of OA diagnosis, prognosis, and treatment evaluation [1]. Synovial fluid is in direct contact with articular cartilage, ligament, meniscus and joint capsule it is therefore an excellent sample to explore the protein profile in which could provide pathogenesis information from several surrounding parts.

Objectives: The aim with this project was to perform mass spectrometry (MS) of human synovial fluid using a global discovery approach, to identify biomarker candidates associated with meniscus degradation and/or knee OA.

Methods: Synovial fluid was sampled from 3 different subject groups: i) end-stage medial compartment knee OA patients undergoing arthroplasty ( $n=11$, age range $55-80$ years), ii) knee arthroscopy patients who typically had a degenerative meniscal tear ( $n=7$, age range 50-64 years), and iii) deceased human donors without known chronic knee disease $(n=13$, age range 19-79 years). All synovial fluids were centrifuged and freshly frozen and stored at $-80^{\circ} \mathrm{C}$. For the analysis, $50 \mu \mathrm{L}$ of synovial fluid was mixed with MS-safe proteinase inhibitor cocktail, hyaluronidase, depleted, reduced, alkylated, precipitated, digested with sequencing grade trypsin (Promega), filtered and desalted. The samples were further analyzed with an EASY-nLC 1000 coupled to an Orbitrap Fusion mass spectrometer 
Abstract THU0422 - Table 2. WOMAC and VAS mean scores at baseline, 2, 6 and 12 months after injection.

\begin{tabular}{|c|c|c|c|c|c|c|c|c|c|c|}
\hline \multicolumn{11}{|c|}{ WOMAC index } \\
\hline & \multicolumn{2}{|l|}{ Pain } & \multicolumn{2}{|c|}{ Stiffness } & \multicolumn{2}{|c|}{ Function } & \multicolumn{2}{|c|}{ Total } & \multicolumn{2}{|c|}{ VAS } \\
\hline & PRGF & $\mathrm{HA}$ & PRGF & $\mathrm{HA}$ & PRGF & $\mathrm{HA}$ & PRGF & $\mathrm{HA}$ & PRGF & $\mathrm{HA}$ \\
\hline Baseline & $8.25 \pm 2.7$ & $8.14 \pm 2.6$ & $2.86 \pm 1.8$ & $2.57 \pm .1 .4$ & $\begin{array}{l}30.75 \\
\pm 8.5\end{array}$ & $29 \pm 8.1$ & $41.96 \pm 11.71$ & $\begin{array}{l}39.71 \\
\pm 10.4\end{array}$ & $7.8 \pm 1.5$ & $7.8 \pm 1.1$ \\
\hline At 2 mo & $4.98 \pm 2.6$ & $5.31 \pm 2.3$ & $1.53 \pm 1.4$ & $1.2 \pm 1.1$ & $\begin{array}{c}19.75 \\
\pm 8.2\end{array}$ & $\begin{array}{c}20.78 \\
\pm 6.6\end{array}$ & $26.25 \pm 11.17$ & $\begin{array}{l}27.37 \\
\pm 9.09\end{array}$ & $4.2 \pm 2.01$ & $4.4 \pm 1.6$ \\
\hline At $6 \mathrm{mo}$ & $\begin{array}{c}5.22 \\
\pm 3.05\end{array}$ & $5.9 \pm 2.3$ & $1.43 \pm 1.5$ & $1.2 \pm 1.2$ & $\begin{array}{c}18.22 \\
\pm 9.9\end{array}$ & $\begin{array}{c}21.12 \\
\pm 6.6\end{array}$ & $24.86 \pm 14$ & $28.35 \pm 9.4$ & $4.3 \pm 2.3$ & $4.7 \pm 1.9$ \\
\hline At $12 \mathrm{mo}$ & $5.47 \pm 2.6$ & $6.3 \pm 2.6$ & $1.8 \pm 1.34$ & $1.6 \pm 1.2$ & $\begin{array}{c}19.82 \\
\pm 8.9\end{array}$ & $\begin{array}{c}24.43 \\
\pm 8.4\end{array}$ & $b_{27.10 \pm 12.3}$ & $\begin{array}{l}32.41 \\
\pm 11.8\end{array}$ & $4.5 \pm 1.7$ & $6.1 \pm 1.8$ \\
\hline P-value Within groups & $<0.0001$ & $<0.0001$ & $<0.0001$ & $<0.0001$ & $<0.0001$ & $<0.0001$ & $<0.0001$ & $<0.0001$ & $<0.0001$ & $<0.0001$ \\
\hline $\begin{array}{l}\text { P-value Between } \\
\text { groups }\end{array}$ & & & & & & & & & & \\
\hline
\end{tabular}

using data-independent acquisition. The raw MS data were further analysed with Spectronaut ${ }^{\mathrm{TM}}$ for protein identification and quant data extraction. Differences in protein levels were analyzed in two steps: 1) Donors vs arthroplasty 2) Between all 3 different groups. Analyses were adjusted for age, gender and weight. Differentially expressed proteins between the groups were clustered using Pearson correlation coefficient as the distance metric.

Results: In total, 529 proteins were identified in the 31 different synovial fluid samples analyzed. Principal component analysis suggested a profound difference between the protein profiles of synovial fluid from donors vs arthroplasty patients, while the arthroscopy group had a protein profile that was in-between donors and the arthroplasty group (Figure 1A). Statistical differential analysis yielded significant differences in the levels of 43 proteins comparing donors vs arthroplasty patients. 36 proteins differed between the 3 groups when comparing all groups in the same statistical model. Extracellular matrix proteins like collagens and aggrecan showed higher expression in donors than in arthroplasty patients. Collagen on the other hand was higher in arthroscopy patients compared to donors. Decorin was significantly higher in donors compared to both arthroscopy and arthroplasty patients. The differentially expressed proteins associated with the inflammatory response were higher in the arthroscopy group compared to both donors and arthroplasty patients. Generally, extracellular matrix proteins like collagen $1 / 2$ were positively correlated with lipoproteins like $A P O B$ and APOA but negatively correlated with acute phase proteins like PON1(Figure 1B).

Conclusion: There is a profound difference in the protein profile of synovial fluid in donors vs knee OA patients (Figure 1). The inflammatory response seems to be higher in the early stages of $O A$ than in later stage. Our findings emphasize the importance of $O A$ staging in the development and use of biomarkers.

\section{REFERENCE:}

[1] Mobasheri A. Osteoarthritis year 2012 in review: biomarkers. Osteoarthritis and Cartilage. 2012 Dec 1;20(12):1451-64.

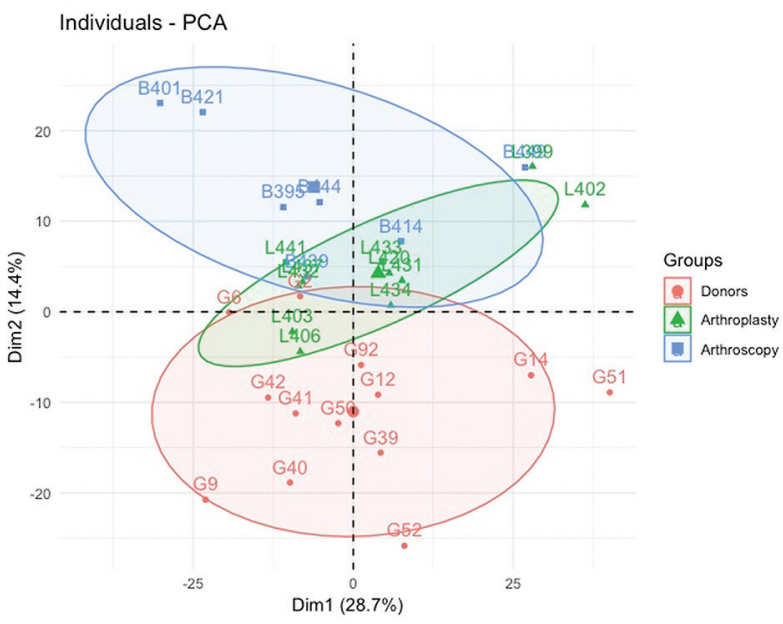

A)

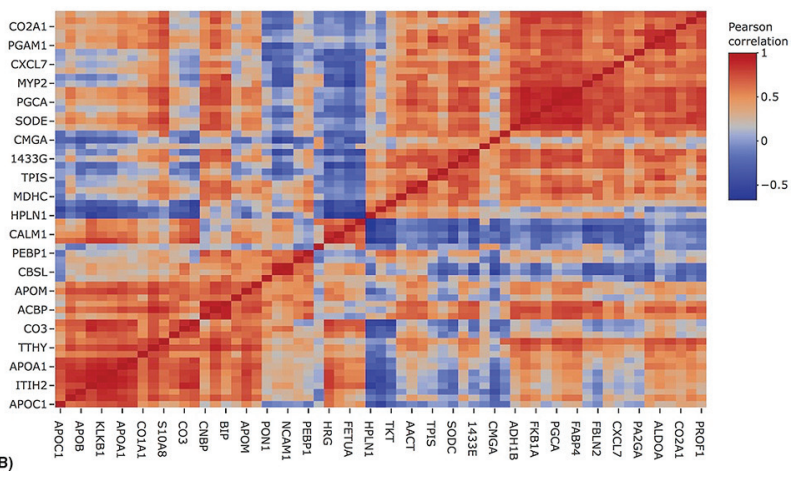

Abstract THU0415 - Figure 1. Data analysis of the protein results. A) Principal component analysis plot of the protein profile from the different groups. B) Pearson correlation matrix of 63 significant differentially expressed proteins presented as gene names on the $y$ - and $x$ axes.

Acknowledgement: We would like to acknowledge the Foundation for Research in Rheumatology (FOREUM) for funding.

Disclosure of Interests: None declared

DOI: 10.1136/annrheumdis-2019-eular.5287

\section{THU0416 \\ PREDICTORS OF RADIOGRAPHIC PROGRESSION IN HAND OSTEOARTHRITIS: A TEN-YEARS PROSPECTIVE COHORT STUDY}

Tine Vanhaverbeke ${ }^{1}$, Lisa Pardaens ${ }^{1}$, Ruth Wittoek ${ }^{2,3} .{ }^{1}$ Ghent University, medical student, Gent, Belgium; ${ }^{2}$ Ghent University Hospital, Rheumatology, Gent, Belgium; ${ }^{3}$ Ghent University, Internal Medicine and Paediatrics, Gent, Belgium

Background: Osteoarthritis $(\mathrm{OA})$ is the most common musculoskeletal dis ease in the general population and is inherent to ageing. ${ }^{1}$ Limited evidence is available on risk factors for radiographic progression in hand $\mathrm{OA}(\mathrm{HOA})$ and in erosive $\mathrm{HOA}^{2} \mathrm{~A}$ previous evaluation of the Ghent 